\title{
Review of Cross-Leg Flaps in Reconstruction of Posttraumatic Lower Extremity Wounds in a Microsurgical Unit
}

\author{
Ravi K. Mahajan ${ }^{1}$ Krishnan Srinivasan ${ }^{1} \quad$ Harish Ghildiyal $^{2} \quad$ Mahipal Singh $^{1} \quad$ Adish Jain $^{1}$ Taha Kapadia ${ }^{1}$ \\ Ankush Tambotra ${ }^{1}$ \\ ${ }^{1}$ Department of Plastic and Reconstructive Surgery, \\ Amandeep Hospital and Clinics, Amritsar, Punjab, India \\ 2Department of Plastic and Reconstructive Surgery, Kailash Hospital, \\ Dehradun, Uttarakhand, India \\ Indian J Plast Surg 2019;52:117-124

\begin{abstract}
Address for correspondence Krishnan Srinivasan, Department of Plastic Surgery, Amandeep Hospital and Clinics, GT Road, Model Town, Amritsar 143001, Punjab, India (e-mail: s.drkrish@gmail.com).
\end{abstract}

\begin{abstract}
Keywords

- cross leg flap

- leg defect

- free flap

Since the advent of microsurgery, and expanding expertise in the field, extensive traumatic wounds of leg have been managed successfully with free tissue transfer. Various patient-related factors may preclude the use of free flaps even in units with available expertise and infrastructure. It is in such situations that the "cross-leg flap" comes into play. In these cases, instead of attempting complicated anastomotic techniques or anastomosis in the zone of trauma, it is better to perform the simpler and more reliable cross-leg flap. In this study, we try to show the utility of a cross-leg flap based on a retrospective study of 198 patients who underwent cross-leg flap in our institute over a period of 15 years extending from November 2003 to March 2018. Materials and methods: Case sheets of all patients who underwent cross-leg flap from November 2003 to March 2018 were reviewed. The location of defect in the leg, the indication for cross-leg flap, the pattern of cross-leg flap, and perioperative complications were noted. Results: A total of 198 patients underwent cross-leg flap for traumatic soft tissue injury of leg during this period. The most common reason for performing cross-leg flap was poor pulsatility of the recipient artery as seen intraoperatively, followed by the economics of the procedure wherein the initial cost of free flap was found significantly higher compared with cross-leg flap. All flaps survived with partial necrosis occurring in 23 patients. All flaps settled well by 2 years' time. Bony union/fracture healing evaluation was not a part of this study. Conclusion: Cross-leg flap is still a useful tool for leg wound coverage even in microsurgical unit in situations precluding free flap coverage.
\end{abstract}

\section{Introduction}

Cross-leg flap was first described by Hamilton in 1854 , and has subsequently been used for the coverage of leg and foot defects in almost all possible locations. ${ }^{1}$ Many varieties of the crossleg procedure have been reported, such as the cross-leg posterior tibial artery perforator flap, ${ }^{2}$ distally based sural artery fasciocutaneous cross-leg flap, ${ }^{3}$ the saphenous neurofasciocutaneous flap, ${ }^{4}$ and the whole leg cross-leg flap described by Bajaj and colleagues in 2000. ${ }^{5}$ These varieties profoundly increase the flexibility and versatility of cross-leg flap.
DOI https://doi.org/

$10.1055 / \mathrm{s}-0039-1688521$ ISSN 0970-0358.
The success of microsurgical free flaps depends on the presence of healthy recipient vessels. Free flaps cannot be used in patients who have extensive lower extremity injury with axial vessel damage, vessel thrombosis, severe peripheral vessel disease, and patients with poor general condition. Further electrical injury, single vessel extremities, and extremities receiving radiotherapy after tumor resection are relative contraindications for free flap. The risk of free flap failure increases in patients who have had previous failed free flap. In these conditions, the cross-leg flap could be a good alternative reconstructive option.
C2 2019 Association of Plastic
Surgeons of India

se terms

()(1) $\Theta \circledast$ 
Performing microsurgical anastomosis could be challenging in pediatric patients below 6 years of age when compared with the simpler cross-leg flap. This study is aimed to review the utility of a cross-leg and technical details to minimize complications and improve flap survival.

\section{Materials and Methods}

This study was performed in conformity with the Declaration of Helsinki and was performed after obtaining institutional ethical committee clearance.

This is a retrospective study of 198 patients who underwent cross-leg flap at our institute, over a period of 15 years extending from November 2003 to March 2018. Case records of all these patients were reviewed. The location of defect in the leg, the indication for cross-leg flap, the type of cross-leg flap, and perioperative complications were noted. In all patients, initial management was as per the International Trauma Life Support protocol. Once general condition was stabilized, patients were taken up for radical debridement by the plastic surgery team and bony fixation by the orthopedic team. Patients were taken up for definitive soft tissue wound coverage, within 72 hours. When the condition of the patients did not allow definitive surgery for wound coverage, negative pressure wound therapy was given, until patient was fit for surgery. Deep vein thrombosis (DVT) prophylaxis was given for 3 weeks in patients who were obese and had their ankle immobilized due to fracture.

\section{Operative Details}

The pattern of cross-leg flap to be used (anteromedially based, superiorly based, inferiorly based) was decided based on the location of the defect.

When the defect was on the upper, or middle one-third of the leg, we used the conventional cross-leg flap, based anteromedially. When the defect involved the lower onethird or ankle and dorsum of the foot, we preferred using the distally based, posterior tibial artery perforator cross-leg flap. Hand-held Doppler was used to mark out the perforator preoperatively. With an exploratory incision the perforator was identified. The base of flap raised could then be sufficiently narrowed. This helps to avoid kinking of the pedicle and attain better range of rotation of flap. We have not islanded the flap as it would be very difficult to manage it postoperatively. The weight of the flap might stretch and occlude the feeding perforator. When the defect is in the upper one-third and more medially located, superiorly based flap (based on the perforator of the posterior tibial artery) provides better inset than a conventional cross-leg flap and hence was the flap of choice.

When raised as conventional random pattern flap, we raise it in a 1:1 ratio, and when as axial, in a 1:3 width to the length ratio. Even longer flaps can be used when the flap is based on the perforator, like inferiorly based, posterior tibial artery perforator cross-leg flap. When based on perforators from major vessels of the leg, vascularity is robust. ${ }^{6}$ External fixator was used to position the legs in appropriate position as it increases the ease of postoperative care, allows proper cleansing of the wound, and allows knee and ankle mobilization. Donor site was skin grafted and dressed with bolster dressing.

Flap insetted on three sides in a tension-free manner keeping the bridging segment as short as possible. There should be no kinking of the bridge segment. This can happen if the segment is long and excess of flap has been raised. In such a situation, the fixator needs to be adjusted appropriately to make sure the bridging segment remains straight and there is no acute bend. In addition, adequate space is left between two legs to provide free circulation of air to keep the area dry.

First delay of the flap was done at 2 weeks. Flap was divided in stages with a $50 \%$ division of flap base in the first delay. If the length-to-breadth ratio is large or if the flap inset is less than $50 \%$ of the circumference of the flap, division of flap was done in three stages. Two-flap delay procedures were performed in such cases, each 3 days apart, under local anesthesia. Delay was done by cutting the flap base from either side in each stage. The final division and inset was done under spinal anesthesia/general anesthesia, after 1 week.

- Table 1 mentions the technical points to consider to improve flap survival and outcome.

\section{Cases}

1. A 25-year-old male presented with compound trauma of the left upper one-third and middle one-third leg (-Fig. 1). As this patient did not have appropriate recipient vessels close to the zone of the trauma, it was decided to perform cross-leg flap to cover the critical area of the wound. Conventional cross-leg flap was done and a Ilizarov fixator applied after 3 months.

2. A 39-year-old male presented with unstable scar on the heel. He had been operated previously for posttraumatic leg wound by split skin graft ( - Fig. 2). As the entire area was scarred, dissecting for a recipient vessel was difficult and unsafe. Hence, a distally based cross-leg flap was done.

Table 1 Technical considerations in cross-leg flap

\begin{tabular}{|c|c|}
\hline \multicolumn{2}{|c|}{ Flap selection based on location } \\
\hline Defect location & Preferred flap type \\
\hline $\begin{array}{l}\text { Knee joint-including } \\
\text { medial aspect }\end{array}$ & $\begin{array}{l}\text { Superiorly based, posterior tibial } \\
\text { artery perforator flap }\end{array}$ \\
\hline $\begin{array}{l}\text { Upper and middle } \\
\text { one-third of the leg }\end{array}$ & Conventional cross-leg flap \\
\hline Lower one-third & $\begin{array}{l}\text { Conventional/distally based } \\
\text { both can be done }\end{array}$ \\
\hline Ankle, dorsum, heel & $\begin{array}{l}\text { Distally based, posterior tibial } \\
\text { artery perforator-based flap }\end{array}$ \\
\hline \multicolumn{2}{|c|}{ Technical considerations to improve outcome } \\
\hline $\begin{array}{l}\text { 1. Appropriate flap select } \\
\text { 2. Use of external fixator } \\
\text { 3. Use of preop Doppler } \\
\text { proximally based axial } \\
\text { 4. Bridge segment to be } \\
\text { bends and kink } \\
\text { 5. Narrow pedicle in axial } \\
\text { 6. Adequate space betwe } \\
\text { hygiene } \\
\text { 7. Delay before flap divisi }\end{array}$ & $\begin{array}{l}\text { to improve mobility } \\
\text { gs to allow physiotherapy and maintain }\end{array}$ \\
\hline
\end{tabular}



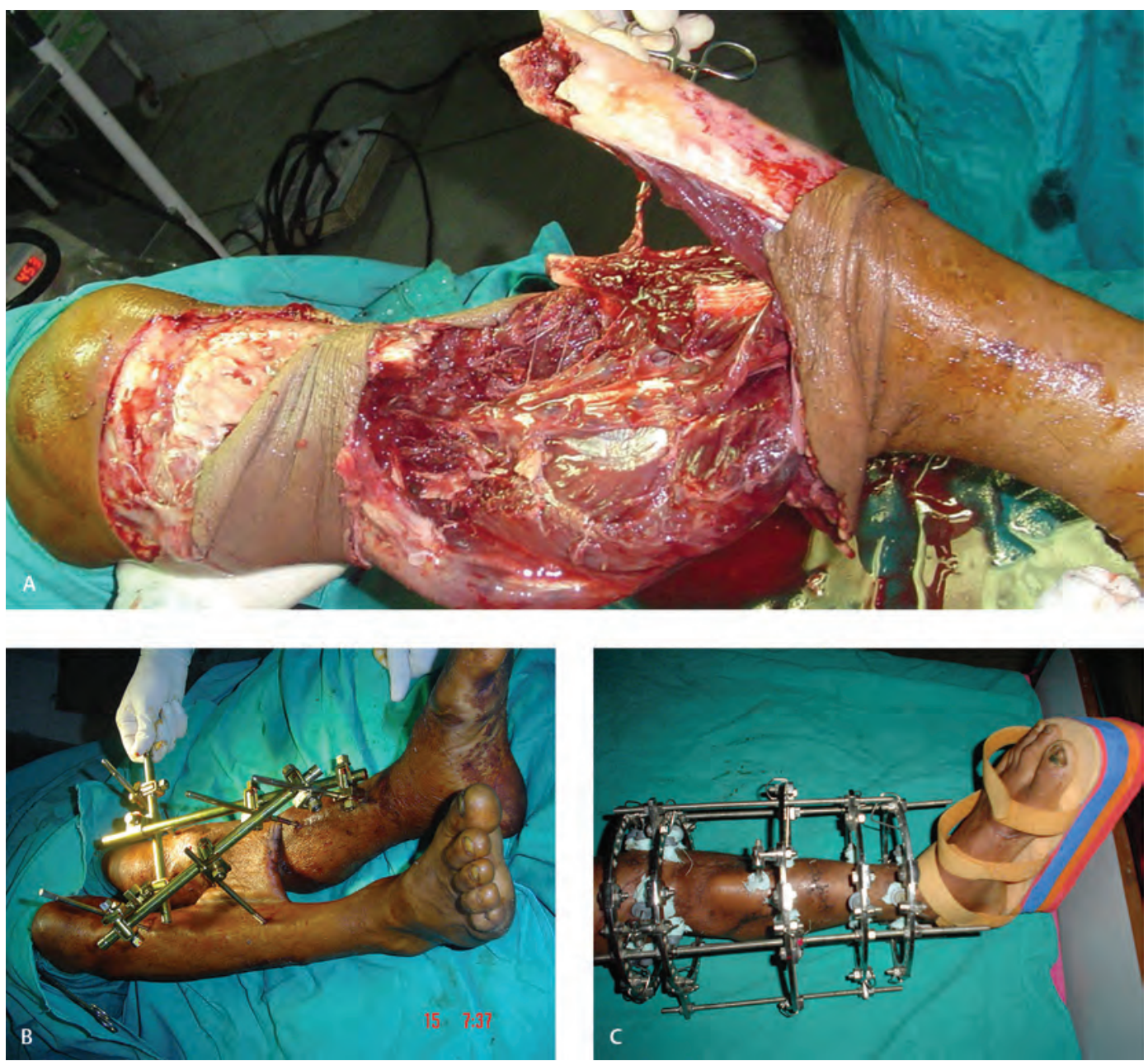

Fig. 1 (A) Left leg compound fracture tibia with defect extending to the knee and involving the upper and middle one-third of the leg. (B) Cross-leg flap inset and legs stabilized using external fixator. (C) Three months post cross-leg flap. Flap settling well. Ilizarov fixator in place for bony distraction.

3. A 23-year-old male presented with lower one-third avulsion

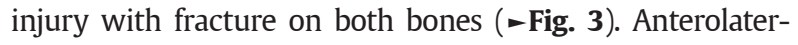
al thigh (ALT) free flap was done at the first stage to cover the wound. But, the flap did not survive. Hence, the flap was debrided and conventional cross-leg flap was done to salvage the limb.

4. A 5-year-old girl presented with Syme's amputation defect of the right foot (- Fig. 4). It was decided to perform cross-leg flap in preference to free flap as it would be a safer option considering the small caliber vessels in this age group. Inferiorly based cross-leg flap was done.

\section{Results}

In the 15 years from 2003 to 2018, a total of 1,090 free flaps for lower limb defects were performed. During the same time period, a total of 198 patients underwent cross-leg flap for traumatic soft tissue injury of the leg, of which 175 patients were male and 23 female. Most patients were in the 40 to 50 age group ( 97 patients, $48.98 \%$ ), followed by patients in the group of 20 to 30 years of age (43 patients, $21.71 \%$ ). Five patients were under the age of 6 years. Seventeen patients underwent cross-leg flap as an elective procedure and the remaining 181 were emergent in nature. Seventeen patients had defect in the upper one-third of the leg, 44 in the middle one-third, 31 in the lower one-third, 45 in the foot and ankle region, and 61 had combinations involving multiple zones of the leg (-Table 2). A total of 123 patients underwent conventional cross-leg flap, of which 14 had defects in the upper one-third of the leg, 41 in the middle one-third, 10 in the lower one-third, and 57 in the combination of defect group. Seven patients had superiorly based flap, mostly for the upper one-third defect and combination defect involving the upper one-third. Sixty-eight patients underwent inferiorly based flaps, out of which 45 were for foot and ankle defects (-Table 2). Among the 198 patients, 51 underwent cross-leg flap due to poor pulsatility of blood observed on table after dividing the recipient artery (-Table 3 ). Twenty-seven patients had a single vessel limb with the other divided vessels too proximal to the zone of trauma for a primary anastomosis to be possible. Forty patients opted out of free flap due to high initial cost compared with the cross-leg flap. Twenty-three were heavy smokers with peripheral vascular disease, who refused to or were unable to stop smoking in the perioperative period. Twenty-eight patients were unfit for prolonged surgery from anesthesia point of view. Seven patients had already undergone one free flap (successful), and hence using up the recipient vessels. Twelve had unsuccessful attempt of free flap cover. Five patients underwent cross-leg 

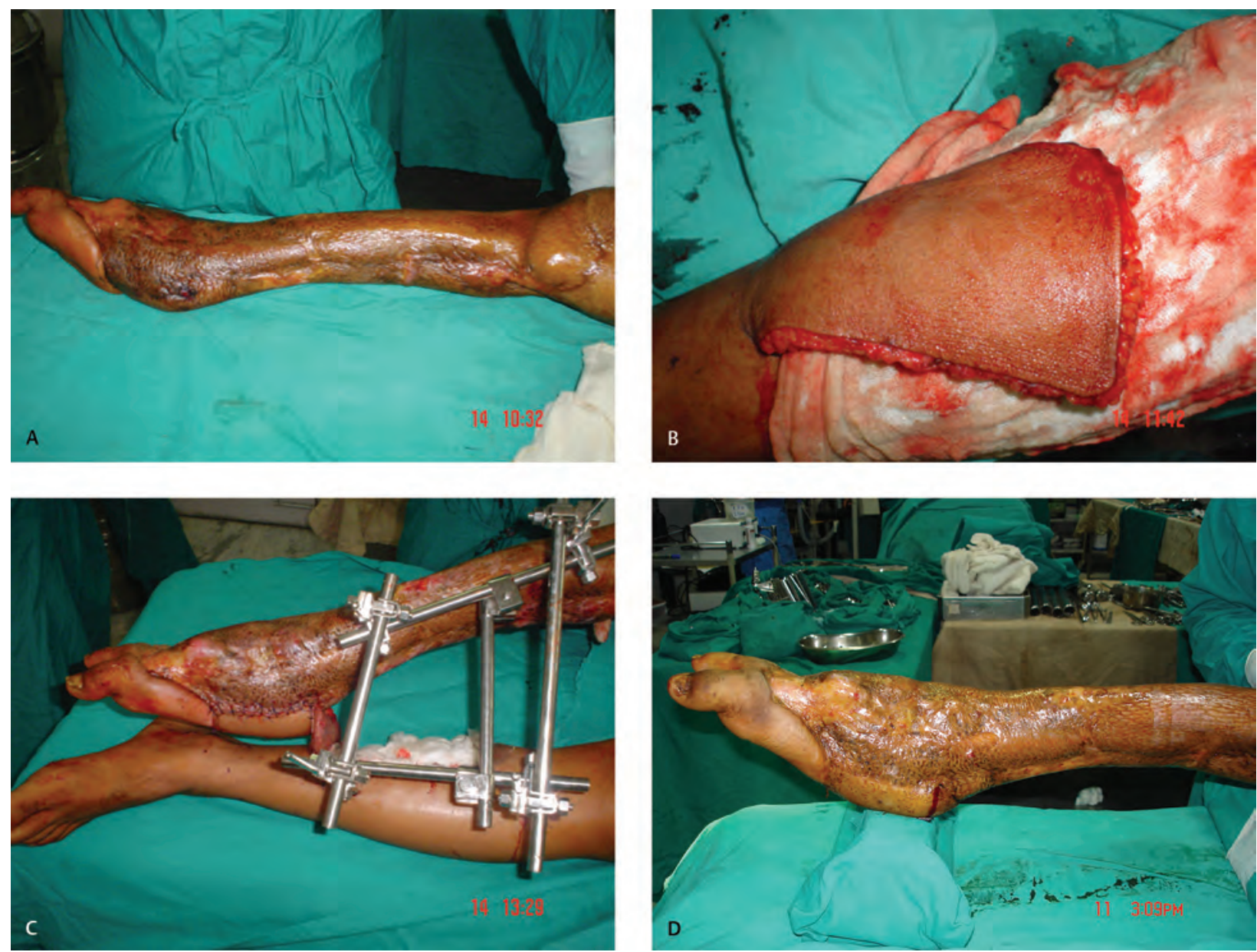

Fig. 2 (A) Right heel unstable scar with extensive scarring of the entire leg. (B) Distally based cross-leg flap raised. (C) Cross-leg flap inset and legs stabilized with external fixator. (D) Cross-leg flap divided and inset done at 3 weeks.

flap as an additional procedure to free flap to provide complete wound cover when the distal part of the free flap necrosed exposing the critical wound area. Five patients who were under the age of 6 years underwent cross-leg flap ( - Table 3 ). Note that $0.5 \%$ patients who were obese and with ankle immobilized due to fracture malleoli were given DVT prophylaxis using low molecular weight heparin (30 mg twice a day subcutaneously) for a period of 3 weeks.

Out of 198 patients who underwent cross-leg flap procedure, 23 patients developed partial necrosis of the flap and were managed with readvancement of the flap. All flaps survived.

Twenty-five patients had to be provided with split thickness skin graft over noncritical areas. Sixteen patients had minor pin track infection which was addressed with local dressing and pin tract care. Eighteen patients were concerned about cosmetic appearance of the donor leg. None of the patients in this study developed any pressure sore over the heel region. None of our patients underwent amputation after cross-leg flap was done. Fracture healing was not a part of this study and was not analyzed. Physiotherapy and weight bearing was decided upon by the orthopedic team depending on the fracture pattern. Secondary procedures were needed in some patients that included bone graft and/or application of plates/Ilizarov fixator for fracture fixation and distraction, respectively. The details of secondary procedures were not a part of this study.

\section{Discussion}

Microsurgical free tissue transfer is now regarded as the gold standard in the management of complex lower extremity trauma in most centers. ${ }^{7-9}$ With more and more training in microsurgery, free flap transfer is being performed with more ease and increased success rate..$^{10}$ This is our first choice for reconstructing lower extremity defects too.

But there are also certain limitations of free flap surgery. Patients with extensive trauma with damage to two major vessels, severe peripheral vascular disease, previous history of free flaps, and nonavailability of suitable recipient vessel are all relative contraindications to free flap surgery. History of smoking, electrical injury, and need for radiation also increase the chance of free flap failure. ${ }^{11}$ These were the indications wherein we used cross-leg flap in preference to free flap.

We had 27 patients with associated vascular injury with the limb surviving on only a single vessel. This criterion is used in other studies too to consider use of cross-leg flap. ${ }^{11}$ In such patients when the two cut vessels are not in a condition to be used for anastomosis, it is only logical to not use 

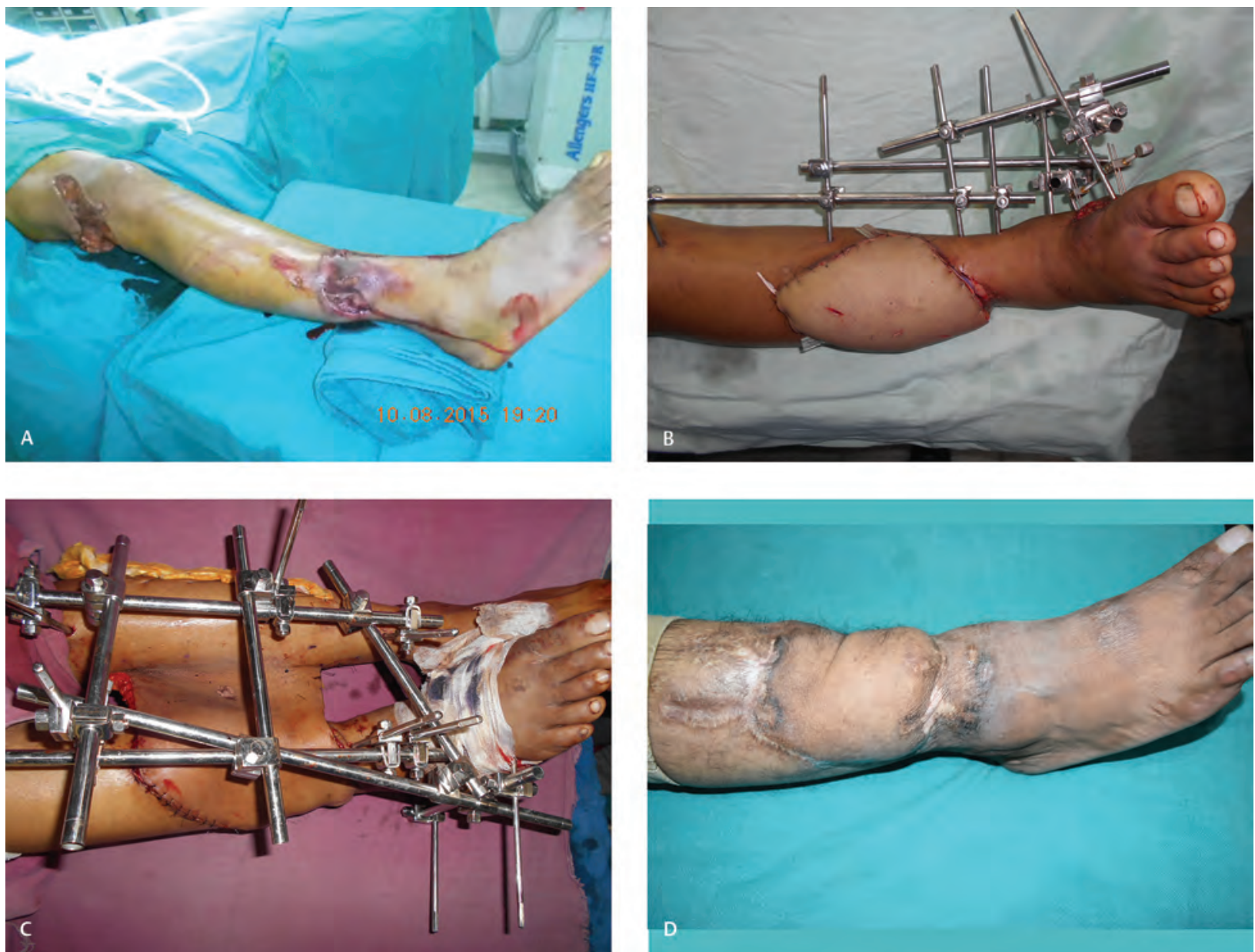

Fig. 3 (A) Right leg lower one-third crush avulsion injury with underlying tibia fracture. (B) Free anterolateral thigh flap done after initial debridement and bony fixation with external fixator. (C) Conventional cross-leg flap done and legs fixed in position using external fixator. (D) Cross-leg flap well settled at 1 year time.
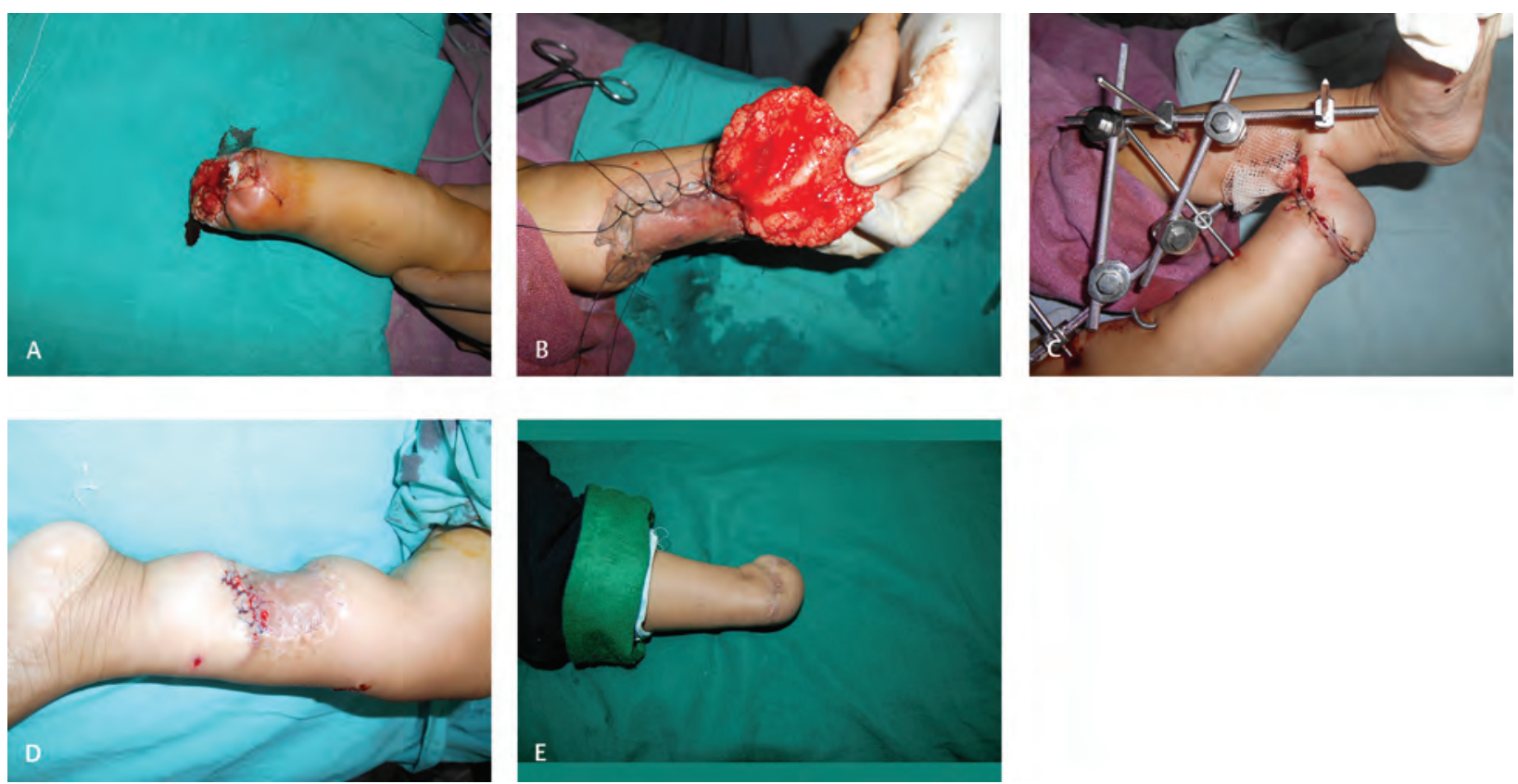

Fig. 4 (A) Syme's amputation stump in a 5-year-old child. (B) Inferiorly based cross-leg flap raised and donor area skin grafted. (C) Flap inset and legs stabilized using external fixator. (D) Cross-leg donor site after flap division and inset. (E) Flap well settled at 1 year. 
Table 2 Location of defect and type of flap done to cover the wound

\begin{tabular}{|l|l|l|l|l|}
\hline Anatomical territory of leg involved & Conventional cross leg & Distally based & Proximally based & Total \\
\hline Upper $1 / 3$ & 14 & 0 & 3 & 17 \\
\hline Middle $1 / 3$ & 41 & 2 & 1 & 44 \\
\hline Lower $1 / 3$ & 10 & 21 & 0 & 31 \\
\hline Foot and ankle & 0 & 45 & 0 & 45 \\
\hline Combination of defects & 57 & 1 & 3 & 61 \\
\hline Total & 123 & 68 & 7 & 198 \\
\hline
\end{tabular}

Table 3 Reason for doing cross-leg flap in preference to free flap

\begin{tabular}{|l|l|l|}
\hline Serial no. & Reasons for change of plan & Number \\
\hline 1 & Economic & 40 \\
\hline 2 & $\begin{array}{l}\text { Associated vascular injury/single } \\
\text { vessel limb }\end{array}$ & 27 \\
\hline 3 & $\begin{array}{l}\text { Poor arterial flow on cutting } \\
\text { intraoperatively }\end{array}$ & 51 \\
\hline 4 & Flap failure (free/local) & 12 \\
\hline 5 & $\begin{array}{l}\text { Comorbid conditions precluding } \\
\text { prolonged surgery }\end{array}$ & 28 \\
\hline 6 & $\begin{array}{l}\text { Peripheral vascular disease/smokers } \\
\text { Previously done free flap (no }\end{array}$ & 23 \\
\hline 7 & $\begin{array}{l}\text { Additional coverage following free } \\
\text { flap distal necrosis }\end{array}$ & 5 \\
\hline 10 & Patients under 6 years of age & 5 \\
\hline 11 & & 198 \\
\hline Total & & \\
\hline
\end{tabular}

the only functioning vessel for anastomosis to free flap as this could compromise the limb vascularity. Flow-through free flaps, like ALT, have been used to reconstruct complex lower extremity wounds with compromised vascularity. ${ }^{12}$ But their use in a vascular limb, risking limb loss if anastomosis fails, is an unreasonable approach. Hence, the alternative in such situations is a cross-leg flap which does not disturb the existing vessel and provides good wound cover.

The quality of recipient vessels is the most important factor in determining the success of free flap..$^{13} \mathrm{~A}$ good recipient artery has a smooth intima and pulsatile bright red flow. ${ }^{14,15}$ We had 51 patients in whom intraoperative finding of poor flow through the recipient vessel was seen. In such cases, we decided not to go ahead with free flap as the chance of failure would be high. Cross-leg flap is the ideal alternative in such cases as it does not depend on the recipient vessel status.

Doing a second free flap in a region of previously failed free flap has a higher rate of complications, due to the presence of traumatized vessels. ${ }^{13,16}$ Also, in a patient who has already undergone one successful free flap, paucity of recipient vessels makes another free flap technically difficult. Taking these factors into consideration, we use cross-leg flap in all secondary reconstructions which would be more reliable than a second free flap.

We had 28 patients with comorbidities (uncontrolled diabetes mellitus and cardiac disease), wherein we preferred to perform cross-leg flap. Such patients generally are unable to withstand prolonged surgical stress. Though not an absolute contraindication, presence of diabetes also increases predisposition to peripheral vascular disease. ${ }^{13}$ Peripheral vessels need to be evaluated to look for good pulsatility. Angiography often performed to determine appropriate recipient vessels. ${ }^{17-19}$ In our study, we did not prefer computed tomography angiogram in any patient, instead, hand-held Doppler was done in cases where distal pulses were not digitally palpable. When no good vessels were detected and when good pulsatile flow was not seen intraoperatively, we avoided doing a free flap. In patients with cardiac problems, fitness to undergo prolonged surgery in the form of free flap may not be possible.

Heavy smoking is also a factor in flap failure. ${ }^{13}$ Patients need to abstain from smoking for 2 weeks prior and after free flap. ${ }^{20}$ In patients who cannot stop smoking or are heavy smokers, we do cross-leg flap to avoid possible vascular complications of free flap. In an emergency setting, patients who have a history smoking or are regular heavy smokers, the chance of free flap failure is higher and it may be advisable to perform cross-leg flap.

In cases of severe polytrauma, patient may not be fit to undergo prolonged surgery and cross-leg flap provides a simpler means of providing wound cover.

High velocity trauma results in complex extensive wounds of the leg which may not be completely covered by any single flap. ${ }^{21,22}$ In such cases, large flaps like the latissimus dorsi + serratus anterior ${ }^{22}$ and BERAM flaps ${ }^{23}$ have been described. But distal portion of such flaps, especially the latissimus dorsi flap, is prone for ischemic necrosis, and when such a complication arises, free flap can be complimented by the use of a cross-leg flap to cover the defect. We had five patients in which this was needed.

We performed cross-leg flap in five pediatric patients. Use of cross-leg flaps in the pediatric age group has been described as a simpler procedure with less chance of complications in other studies. ${ }^{24}$ Though we do perform free flaps in pediatric age groups, in large leg defects, and very young children (under 6 years of age), finding a large donor tissue may be difficult and in such situations we found crossleg flap to be a very useful option.

In all the above-mentioned situations, we see that use of free flap poses an increased chance of complications than the average failure rate in a high volume microsurgical unit (a success rate ranging from 95 to $99 \%$ ). ${ }^{16,25,26}$ In such cases, it is preferable to do a flap that is not dependent on microvascular anastomosis. When the other leg is not 


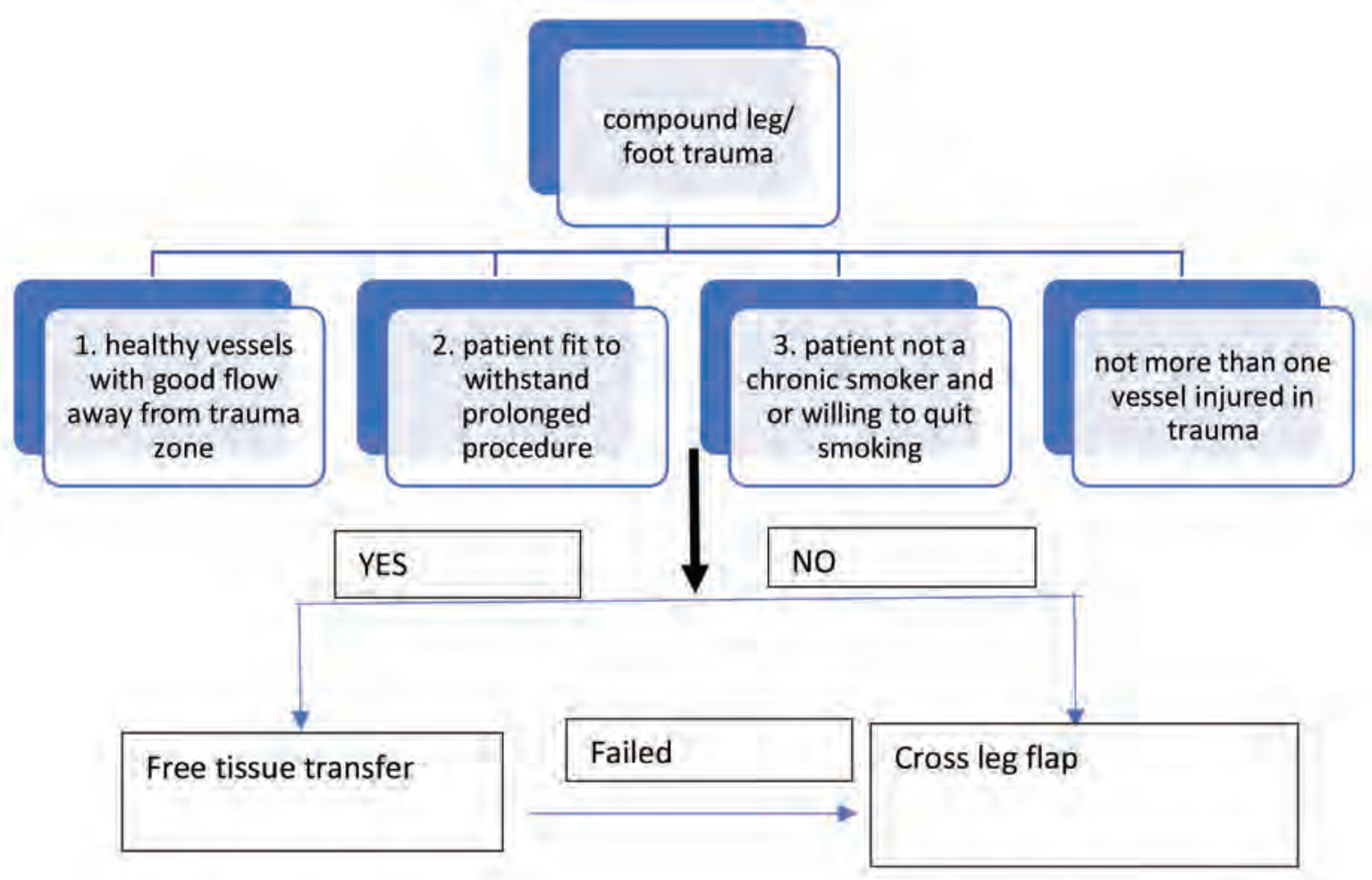

Fig. 5 Algorithm showing indications for cross-leg flap in leg trauma.

involved in trauma, cross-leg flap provides a very good option for reliable wound cover.

In relation to fracture healing, recent studies show that no difference exists in fracture healing between muscle flap and fasciocutaneous flap. ${ }^{27,28}$

Despite all the advances in free flap surgery and newer nonsurgical wound management modalities, as we have seen above, there are occasions where the wounds are not appropriately managed by these techniques and in these cases a cross-leg flap becomes a good alternative. ${ }^{29,30}$

In fact, in their series of 56 patients with lower extremity trauma, Lu et al describe the use of cross-leg flap as the first choice flap in preference to free flap..$^{11}$ Though we use crossleg flap in selective cases, this study suggests the reliability, ease, and versatility of cross-leg flaps. As has been mentioned previously, the cross-leg flap can utilize almost entire leg skin based on the septocutaneous perforators, ${ }^{5}$ can be raised as a random pattern fasciocutaneous flap, ${ }^{31}$ distally or proximally based perforator flaps, ${ }^{29}$ perforator plus flaps,,$^{32}$ myocutaneous flaps, ${ }^{33}$ and sural artery flap. ${ }^{29}$ Use of perforator-based flap makes it possible to raise flap of greater length and narrower pedicle. $^{34}$ This means that almost any area of the leg can be covered using a cross-leg flap. Use of external fixator has simplified immobilization and helps in giving good postoperative care. ${ }^{29}$ We follow similar practice of using external fixator to immobilize the extremities.

Some authors have recommended using cross-leg flap as the first line treatment in preference to a free flap. ${ }^{11}$ But we do not agree with this because most of our patients with high velocity trauma have extensive wounds which are three-dimensional in nature. The wound cavity is not filled enough by a fasciocutaneous cross-leg flap as appropriately as a free muscle flap. Hence, our first choice in all these patients is free muscle flap. It is only when free flap cannot be done, that we use the cross leg flap.

In the long term, almost total sensory recovery at the flap site has been reported (in $\sim 2$ years' time), ${ }^{35}$ whereas donor site return of sensation is reported to be poor in the same study. Appearance wise, all our patients were satisfied with the flap appearance but the problem was with the donor site which was scarred and depressed. This is especially so in female patients. Similar finding was observed by Morris and Buchan ${ }^{35}$ in their study of 165 patients and they suggested use of reverse dermal fat flap to circumvent donor site depressed scar.

The problem with cross-leg flap arises in elderly patients who are prone for joint stiffness and in patients who have hypercoagulable state wherein the chance of DVT increases. ${ }^{11}$ We had five patients who were obese and had their ankle immobilized. Thromboprophylaxis with low molecular weight heparin was given in these patients for a period of 3 weeks. In patients prone for stiffness and in arthritic patients, we avoid the use of cross-leg flaps. In hypercoagulable states, thromboprophylaxis is given and patient can be taken up for cross-leg flap, maintaining anticoagulation after the procedure till division. ${ }^{11}$ Use of external fixator helps by allowing the physiotherapy team to proceed thereby reducing stiffness in the foot and ankle and helps reduce the chance of DVT. In their study, Lu et al train the flap and divide it on an average of 11 days. ${ }^{11}$ This would reduce hospitalization time dramatically. We still divide the flap at 21 days. Other complications are in the form of partial flap necrosis which can be managed by debridement and dressings most of the times. 


\section{Conclusion}

We find that cross-leg flap with all its variations, is a good alternative for providing coverage in complex lower extremity wounds even in a microsurgical unit, in specific situations that preclude free flap surgery (-Fig. 5).

\section{Conflict of Interest}

None.

\section{References}

1 Sharma RK, Kola G. Cross leg posterior tibial artery fasciocutaneous island flap for reconstruction of lower leg defects. $\mathrm{Br} J$ Plast Surg 1992;45(1):62-65

2 Georgescu AV, Irina C, Ileana M. Cross-leg tibial posterior perforator flap. Microsurgery 2007;27(5):379-383

3 Basile A, Stopponi M, Loreti A, Minniti de Simeonibus AU. Heel coverage using a distally based sural artery fasciocutaneous cross-leg flap: report of a small series. J Foot Ankle Surg 2008;47(2):112-117

4 Yildirim S, Akan M, Giderodğlu K, Aköz T. Use of distally based saphenous neurofasciocutaneous and musculofasciocutaneous cross-leg flaps in limb salvage. Ann Plast Surg 2001;47(5):568-574

5 Kohli JS, Pande S, Bajaj SP. Large transverse fasciocutaneous leg flap: whole leg flap. Br J Plast Surg 2000;53(6):495-498

6 Wang ZQ Cao YL, Huang YF, Liu DQ Li XF. Cross-leg repair of large soft-tissue defects in distal sites of the feet by distally based neuro-fasciocutaneous flaps with perforating vessels. Genet Mol Res 2014;13(3):5484-5491

7 Francel TJ, Vander Kolk CA, Hoopes JE, Manson PN, Yaremchuk MJ. Microvascular soft-tissue transplantation for reconstruction of acute open tibial fractures: timing of coverage and long-term functional results. Plast Reconstr Surg 1992;89(3):478-487, discussion 488-489

8 Khouri RK, Shaw WW. Reconstruction of the lower extremity with microvascular free flaps: a 10-year experience with 304 consecutive cases. J Trauma 1989;29(8):1086-1094

9 Heller L, Levin LS. Lower extremity microsurgical reconstruction. Plast Reconstr Surg 2001;108(4):1029-1041, quiz 1042

10 Percival NJ, Sykes PJ, Earley MJ. Free flap surgery: the Welsh Regional Unit experience. Br J Plast Surg 1989;42(4):435-440

11 Lu L, Liu A, Zhu L, Zhang J, Zhu X, Jiang H. Cross-leg flaps: our preferred alternative to free flaps in the treatment of complex traumatic lower extremity wounds. J Am Coll Surg 2013;217(3):461-471

12 Qing L, Wu P, Liang J, Yu F, Wang C, Tang J. Use of flow-through anterolateral thigh perforator flaps in reconstruction of complex extremity defects. J Reconstr Microsurg 2015;31(8):571-578

13 Koul AR, Patil RK, Nahar S. Unfavourable results in free tissue transfer. Indian J Plast Surg 2013;46(2):247-255

14 Koul AR, Patil RK, Philip VK. Early use of microvascular free tissue transfer in the management of electrical injuries. Burns 2008;34(5):681-687

15 Park S, Han SH, Lee TJ. Algorithm for recipient vessel selection in free tissue transfer to the lower extremity. Plast Reconstr Surg 1999;103(7):1937-1948

16 Nakatsuka T, Harii K, Asato H, et al. Analytic review of 2372 free flap transfers for head and neck reconstruction following cancer resection. J Reconstr Microsurg 2003;19(6):363-368, discussion 369
17 Khouri RK, Cooley BC, Kunselman AR, et al. A prospective study of microvascular free-flap surgery and outcome. Plast Reconstr Surg 1998;102(3):711-721

18 Nahabedian MY, Singh N, Deune EG, Silverman R, Tufaro AP. Recipient vessel analysis for microvascular reconstruction of the head and neck. Ann Plast Surg 2004;52(2):148-155, discussion 156-157

19 Colen LB, Stevenson A, Sidorov V, et al. Microvascular anastomotic thrombosis in experimental diabetes mellitus. Plast Reconstr Surg 1997;99(1):156-162

20 Gu YD, Zhang GM, Zhang LY, Li FG, Jiang JF. Clinical and experimental studies of cigarette smoking in microvascular tissue transfers. Microsurgery 1993;14(6):391-397

21 Kim SW, Youn S, Kim JD, Kim JT, Hwang KT, Kim YH. Reconstruction of extensive lower limb defects with thoracodorsal axis chimeric flaps. Plast Reconstr Surg 2013;132(2):470-479

22 Mahajan RK, Srinivasan K, Bhamre A, Singh M, Kumar P, Tambotra A. A retrospective analysis of latissimus dorsi-serratus anterior chimeric flap reconstruction in 47 patients with extensive lower extremity trauma. Indian J Plast Surg 2018;51(1):24-32

23 Koul AR, Nahar S, Prabhu J, Kale SM, Kumar PH. Free boomerang-shaped extended rectus abdominis myocutaneous flap: the longest possible skin/myocutaneous free flap for soft tissue reconstruction of extremities. Indian J Plast Surg 2011;44(3):396-404

24 Kapadia A, Cheruvu VR, John JR, Tripathy S, Sharma RK. Reconstruction in pediatric orthopedic trauma: the role of primary cross leg flap cover. J Pediatr Orthop B 2017; 26(2):172-178

25 Bui DT, Cordeiro PG, Hu QY, Disa JJ, Pusic A, Mehrara BJ. Free flap reexploration: indications, treatment, and outcomes in 1193 free flaps. Plast Reconstr Surg 2007;119(7):2092-2100

26 Pohlenz P, Blessmann M, Blake F, Li L, Schmelzle R, Heiland M. Outcome and complications of 540 microvascular free flaps: the Hamburg experience. Clin Oral Investig 2007;11(1):89-92

27 Cho EH, Shammas RL, Carney MJ, et al. Muscle versus fasciocutaneous free flaps in lower extremity traumatic reconstruction: a multicenter outcomes analysis. Plast Reconstr Surg 2018;141(1):191-199

28 Hong JP, Shin HW, Kim JJ, Wei FC, Chung YK. The use of anterolateral thigh perforator flaps in chronic osteomyelitis of the lower extremity. Plast Reconstr Surg 2005;115(1):142-147

29 Reisler T, Buziashvili D, Liu FC, Datiashvili RO. Revisiting the fasciocutaneous perforator cross-leg flap. Eplasty 2016; 16:ic16

30 Long CD, Granick MS, Solomon MP. The cross-leg flap revisited. Ann Plast Surg 1993;30(6):560-563

31 Perez Macias JM. Reconstruction of the foot and lower leg by a fasciocutaneous cross-leg flap after traumatic amputation and circumferential soft-tissue loss. Chir Plast. 1986;8:187-191

32 Sharma RK, Mehrotra S, Nanda V. The perforator "plus" flap: a simple nomenclature for locoregional perforator-based flaps. Plast Reconstr Surg 2005;116(6):1838-1839

33 Ingianni G, Mfihlbauer W. The musculo-cutaneous cross leg flap. Chir Plastica (Berl) 1979;4:289-292

34 Kamath BJ, Varghese T, Bhardwaj P. Tips and techniques: a modified cross leg flap for large triangular defects of the foot and ankle. Foot Ankle J 2008;1(8):5

35 Morris AM, Buchan AC. The place of the cross-leg flap in reconstructive surgery of the lower leg and foot: a review of 165 cases. Br J Plast Surg 1978;31(2):138-142 